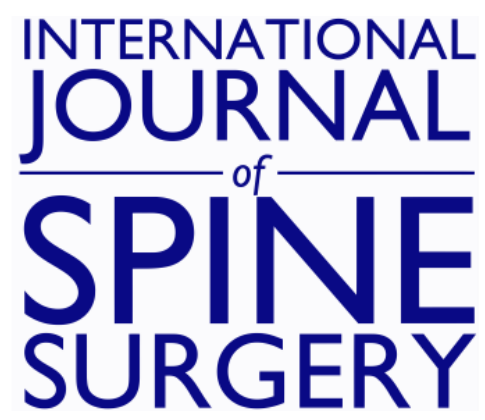

\title{
Iliac Bars Lever Reduction and Fixation System Used in the Treatment of Spondylolisthesis
}

Yingze Zhang, Yong Shen, Dalong Yang, Guochuan Zhang, Chaohui Song and Junming Cao

Int J Spine Surg 2008, 2 (1) 48-54

doi: https://doi.org/10.1016/SASJ-2007-0110-NT

http://ijssurgery.com/content/2/1/48

This information is current as of April 26, 2023.

Email Alerts Receive free email-alerts when new articles cite this article. Sign up at:

http://ijssurgery.com/alerts

The International Journal of Spine Surgery

2397 Waterbury Circle, Suite 1,

Aurora, IL 60504, Phone: +1-630-375-1432

(C) 2008 ISASS. All Righfso Refservededom http://ijssurgery.com/ by guest on April 26, 2023 


\title{
Iliac Bars Lever Reduction and Fixation System Used in the Treatment of Spondylolisthesis
}

\author{
Yingze Zhang, MD, PhD, Yong Shen, MD, PhD, Dalong Yang, $M D$, \\ Guochuan Zhang, $M D, P h D$, Chaohui Song, $M D$, Junming Cao, $M D$
}

\begin{abstract}
Background

The purpose of the current study was to use the Iliac Bars Lever Reduction and Fixation System (IBLRFS) for Grades 1 and 2 spondylolytic spondylolisthesis, evaluate its stability and reductive efficacy, and examine the complications.

\section{Methods}

Between April 2005 and August 2006, 44 patients with Grades 1 and 2 spondylolytic spondylolisthesis were treated surgically: 21 patients underwent posterior Iliac Bars Lever Reduction and Fixation (IBRLFS), 23 patients were treated with traditional stabilization and reduction systems (SRS). The follow-up periods ranged from 1 to 2 years (mean, 1 year and 2 months). The clinical outcome, fusion rate, average percentile degree of displacement, displacement angle, sacral inclination, ratio of intervertebral height, and complications were evaluated. Operating time, blood loss, and duration of hospital stay were compared.
\end{abstract}

\section{Results}

There were no statistically significant differences between the 2 groups in blood loss, recovery rate, and radiographic results. However, there were statistically significant differences in operating time $(P<.05)$, duration of hospital stay $(P$ $<.05)$. There were no cases of nonunion in the two groups. In the IBLRFS group, preoperatively, the average percentile degree of displacement, displacement angle, sacral inclination, and ratio of intervertebral height were $23.48 \% \pm 5.36 \%$, $2.2^{\circ} \pm 1.1^{\circ}, 29.4^{\circ} \pm 6.5^{\circ}$, and $0.68 \pm 0.21$, respectively. Postoperatively, the respective measurements were $6.47 \% \pm 1.49 \%$, $10.3^{\circ} \pm 3.3^{\circ}, 42.6^{\circ} \pm 8.1^{\circ}$, and $0.85 \pm 0.12$. No patients experienced major complications.

In the SRS group, preoperatively, the average percentile degree of displacement, displacement angle, sacral inclination, and ratio of intervertebral height were $21.78 \% \pm 5.16 \%, 2.3^{\circ} \pm 1.0^{\circ}, 26.4^{\circ} \pm 8.5^{\circ}$, and $0.62 \pm 0.25$, respectively. Postoperatively, the respective measurements were $6.34 \% \pm 2.01 \%, 9.8^{\circ} \pm 2.1^{\circ}, 44.1^{\circ} \pm 7.6^{\circ}$, and $0.79 \pm 0.23$. One patient experienced a badly placed screw in the right pedicle of lumbar 4 .

\section{Conclusions}

This kind of new fixation system (IBLRFS) was shown to be useful in the treatment of spondylolisthesis, and its use was associated with minimal complications after 14 months of mean follow-up.

\section{Level of Evidence}

Therapeutic, case studies (level 4).

Key Words: Fusion, spondylolisthesis, fixation, reduction. SAS Journal. Winter 2008. 2:48-54. DOI: SASJ-2007-0110NT

\section{INTRODUCTION}

Spondylolisthesis is a rather common disease that causes severe disability in afflicted patients. ${ }^{1}$ Most adults with spondylolisthesis are asymptomatic. If symptoms develop, they usually consist of back pain, leg pain, or both. The possible sources of pain are the disc, nerve entrapment caused by foraminal stenosis, facet joint arthrosis, and segmental instability. ${ }^{2}$ Because of the general success of conservative treatment of symptomatic spondylolysis, surgical intervention is not usually necessary. The primary indication for surgical treatment of spondylolisthesis is continued pain despite a minimum of 6 months of bracing. Surgical treatment consists of either arthrodesis of the involved motion segment or direct repair of the pars defect.

Some devices for treating spondylolisthesis result in ineffective deformity reduction because of flaws in their structure; others are more effective, but excessive stress concentrated on the 
Table 1. Preoperative and Postoperative Results of Two Treatment Groups

\begin{tabular}{|c|c|c|c|c|}
\hline & \multicolumn{2}{|c|}{ IBLRFS } & \multicolumn{2}{|c|}{ SRS } \\
\hline & Preoperative & Postoperative & Preoperative & Postoperative \\
\hline $\begin{array}{l}\text { Percentile degree of } \\
\text { displacement (\%) }\end{array}$ & $23.48 \pm 5.36$ & $6.47 \pm 1.49$ & $21.78 \pm 5.16$ & $6.34 \pm 2.01$ \\
\hline Displacement angle $\left({ }^{\circ}\right)$ & $2.2 \pm 1.1$ & $10.3 \pm 3.3$ & $2.3 \pm 1.0$ & $9.8 \pm 2.1$ \\
\hline Sacral inclination $\left({ }^{\circ}\right)$ & $29.4 \pm 6.5$ & $42.6 \pm 8.1$ & $26.4 \pm 8.5$ & $44.1 \pm 7.6$ \\
\hline $\begin{array}{l}\text { Ratio of intervertebral } \\
\text { height }^{*}\end{array}$ & $0.68 \pm 0.21$ & $0.85 \pm 0.12$ & $0.62 \pm 0.25$ & $0.79 \pm 0.23$ \\
\hline
\end{tabular}

*Ratio of intervertebral height of slip segment to superior segment

angular part of the pedicle screw can rupture the structure of the device. The technique of pedicle screw placement has been advocated by many spinal surgeons. Although pedicle screw fixation opened new horizons for spinal surgery by providing rigid fixation of the spine, it is a technically demanding procedure with potential complications.

The purpose of the current study was to use the Iliac Bars Lever Reduction and Fixation System (IBLRFS) (an investigational device approved for use in China) for Grades 1 and 2 spondylolytic spondylolisthesis, evaluate its stability and reductive efficacy, and examine the complications.

\section{Figure 1.}

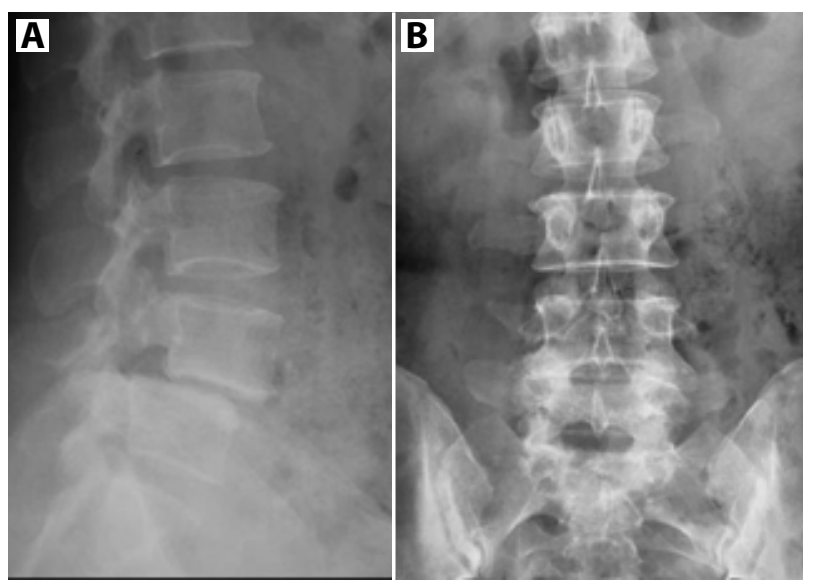

Preoperative lateral (A) and anteroposterior (B) radiographs of an individual with a Grade II lytic spondylolisthesis at L4

\section{MATERIALS AND METHODS}

Between April 2005 and August 2006, 44 patients with Grades 1 and 2 spondylolisthesis 3 were treated surgically: 21 patients underwent insertion of posterior Iliac Bars Lever Reduction and Fixation Systems, 23 patients were treated with traditional stabilization and reduction systems (SRS). The follow-up periods ranged from 1 to 2 years (mean, 1 year and 2 months).

The IBLRFS group consisted of 12 females and 9 males; the mean age was 55.2 years (range, 36-67). Sixteen patients had preoperative back pain, 5 patients had neurogenic claudication, and 12 patients had radicular leg pain. Motor weakness was present in 6 patients, sensory deficit in 10 patients, and combined motor and sensory deficit in 4 patients. The involved level was L4-L5 in 7 patients and L5-S1 in 14 patients. Eight patients were Meyerding Grade 1, and 13 were Grade 2 isthmic spondylolisthesis.

The SRS group consisted of 13 females and 10 males; the mean age was 54.3 years (range, 35-65). Back pain was present in 18 patients, neurogenic claudication in 5 patients, and radicular leg pain in 10 patients. Motor weakness was present in 7 patients, sensory deficit in 13 patients, and combined motor and sensory deficit in 4 patients. The involved level was L4-L5 in 9 patients and L5-S1 in 14 patients. Seven patients were Meyerding Grade 1, and 16 were Grade 2 isthmic spondylolisthesis. There were no statistically significant differences between the 2 groups in age, sex, involved segments, or Meyerding Grade. Preoperative radiographs including standing anteroposterior, lateral (Figure 1), bilateral oblique (Figure 2), and lateral flexion-extension films confirmed spondylolytic spondylolisthesis. Surgical 
indications included disabling back and lower limb symptoms refractory to at least 3 months of conservative management.

\section{Figure 2.}

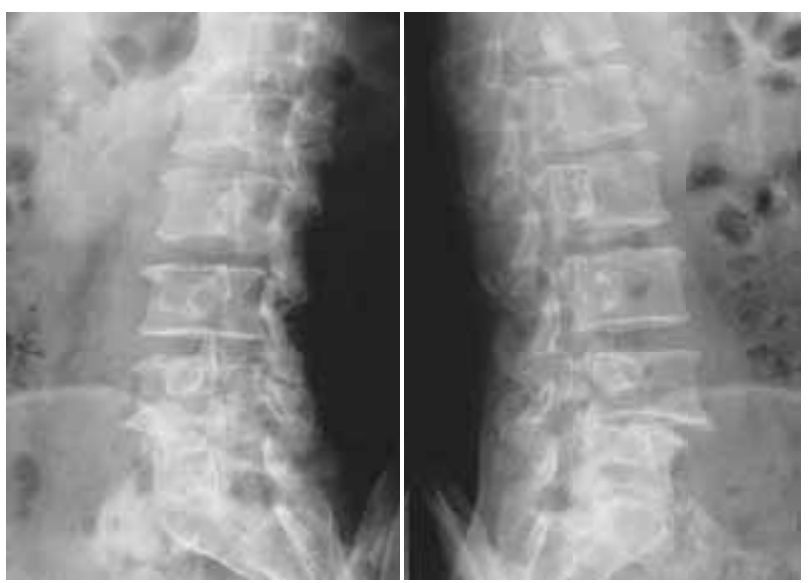

Preoperative bilateral radiographs. The defect is seen in the lucent gap in the are of the pars at L4.

The surgical outcome was evaluated using the Japanese Orthopaedic Association's Assessment of Treatment of Low Back Pain (JOA score). ${ }^{4}$ The recovery rate was calculated using the following formula: (postoperative score - preoperative score $) /(29$ - preoperative score) x $100(\%)$. Plain radiograph analysis was used to evaluate fusion status. The placement of the instrumentation was evaluated by two investigators who were not involved in the surgery or the postoperative care of these patients. Neurologic complications were assessed by review of preoperative, immediate postoperative, and clinical follow-up neurologic examinations. Instrumentation failure included screw breakage, rod breakage, or decoupling

\section{Figure 3.}

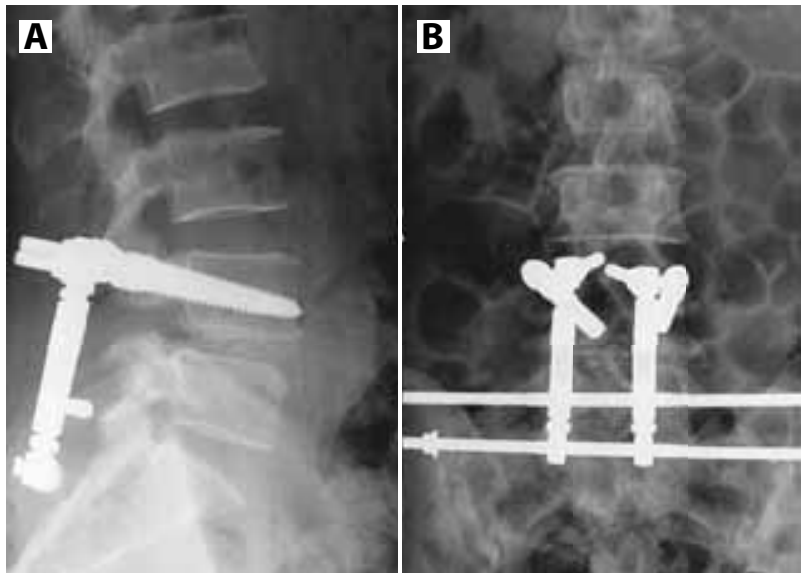

Postoperative lateral (A) and anteroposterior (B) radiographs show the slippage was corrected. of rod and screw as judged on plain radiographs. Union was defined as solid when there was bony trabecular continuity and less than $4^{\circ}$ mobility between the segments on flexionextension stress radiographs. ${ }^{5}$ We measured the percentile degree of displacement, the displacement angle, and the sacral inclination according to Bradford ${ }^{6}$ before and after operation (Figure 3). The ratio of intervertebral height of slip segment to superior segment was also evaluated. Operating time, blood loss, and duration of hospital stay were compared.

\section{SURGICAL TECHNIQUE}

The same surgeon performed all procedures. In the IBLRFS group, each patient was placed on a suitable spine frame in the prone position with the hip in extension to maintain lumbar lordosis and assist in reducing any existing spondylolisthesis. A midline posterior incision was made, and the pathological segment was exposed. The slipped vertebra was instrumented with pedicle screws. Then the laminectomy, medial facetectomy, and foraminotomy were performed. Intraoperative radiographs were taken to confirm the level. The disc nucleus was removed entirely, and the endplate was curetted to the bleeding cancellous bone. And the local autogenous bone graft by laminectomy and facetectomy was used in the space for distraction and anterior column support.

At this point the incision was extended to the $\mathrm{S} 3$, and musculus sacrospinalis was peeled off to the ala of ilium. (The posterior branch of sacral nerves should be protected.) The angular lift

\section{Figure 4.}

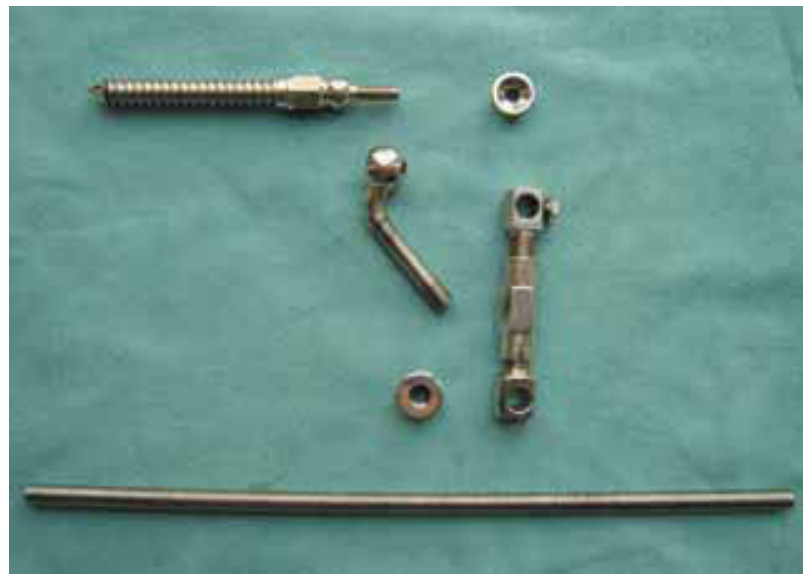

The composition of the IBLRFS

was connected with the pedicle screw and then fixed by nut A. Next, the angular lift was drilled through the round hole in the proximal end of the reduction rod and was fixed by nut B. On the surface and $15 \mathrm{~mm}$ under the posterior superior iliac spine, which clings to the sacrum, the halter was driven in, and then the halter was drilled through the round hole in the distal end of reduction rod. (The interval between the reduction rod and the angular lift should be 10-15 mm.) The support bar was 
Figure 5.

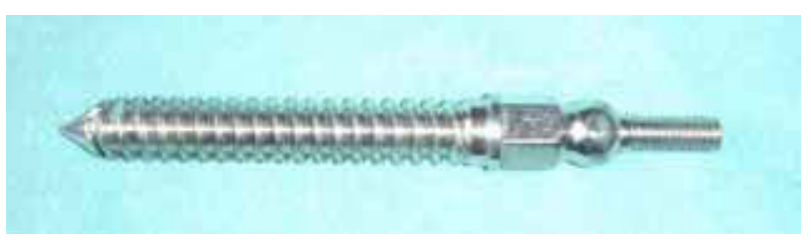

Pedicle screw

driven into the ala of ilium parallel with the halter, assuring the support bar and the halter were touching passively. Then nut B was tightened.

The reduction mechanism of IBLRFS is designed to utilize the foothold of the proximal bar and reduce the slippage of the vertebra. After one week of bed rest, patients were allowed to ambulate with a hard corset. The corset was used for about 3-4 months.

In the SRS group, posterior lumbar interbody fusion with pedicle screw fixation was performed.

\section{RESULTS}

In the IBLRFS group, the mean operative time was 183.7 minutes, and mean blood loss was $759.7 \mathrm{~mL}$. The mean duration of hospital stay was 6.8 days with the mean recovery rate at $88.3 \%$. Preoperatively, the average percentile degree of displacement, displacement angle, sacral inclination, and the ratio of intervertebral height were $23.48 \% \pm 5.36 \%, 2.2^{\circ} \pm 1.1^{\circ}$, $29.4^{\circ} \pm 6.5^{\circ}$, and $0.68 \pm 0.21$, respectively. Postoperatively, these measurements were $6.47 \% \pm 1.49 \%, 10.3^{\circ} \pm 3.3^{\circ}, 42.6^{\circ}$ $\pm 8.1^{\circ}$, and $0.85 \pm 0.12$.

In the SRS group, the mean operative time was 156.6 minutes, and mean blood loss was $763.8 \mathrm{~mL}$. The mean duration of hospital stay was 5.5 days with the mean recovery rate

\section{Figure 6.}

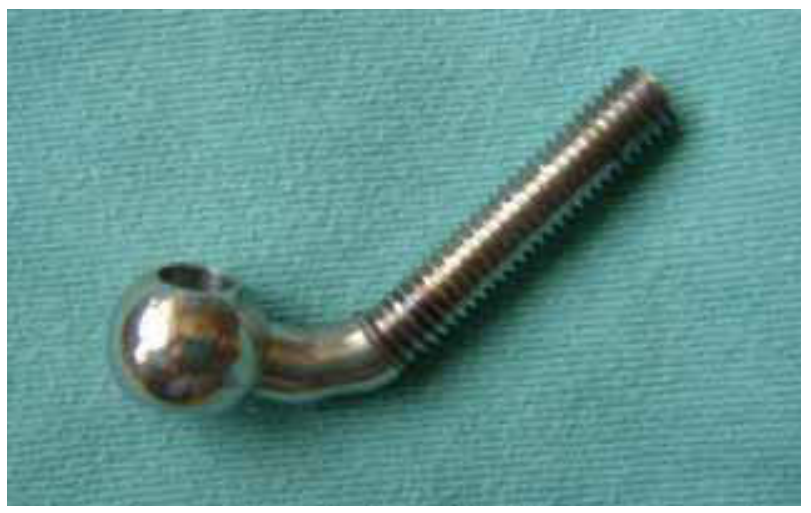

Angular lift at $89.4 \%$. Preoperatively, the average percentile degree of displacement, displacement angle, sacral inclination, and the ratio of intervertebral height were $21.78 \% \pm 5.16 \%, 2.3^{\circ} \pm 1.0^{\circ}$, $26.4^{\circ} \pm 8.5^{\circ}$, and $0.62 \pm 0.25$, respectively. Postoperatively, these respective measurements were $6.34 \% \pm 2.01 \%, 9.8^{\circ} \pm$ $2.1^{\circ}, 44.1^{\circ} \pm 7.6^{\circ}$, and $0.79 \pm 0.23$ (Table 1 ).

There were no statistically significant differences between the two groups in blood loss, recovery rate, and radiographic results. However, there were statistically significant differences in operating time $(P<.05)$ and duration of hospital stay $(P<.05)$. There were no cases of nonunion in the 2 groups. In the IBLRFS group, none of the patients experienced major complications including major vessel injury, neurologic damage, or nerve root injury. There was one case of superficial wound dehiscence, which was treated with antibiotics alone. In one case a diabetic patient suffered a deep wound infection and underwent irrigation and debridement 7 days postoperatively, along with antibiotic treatment. In both cases, the wounds healed satisfactorily. One patient required further surgery to have the instrumentation removed following a fall 2 months after the operation for the

\section{Figure 7.}

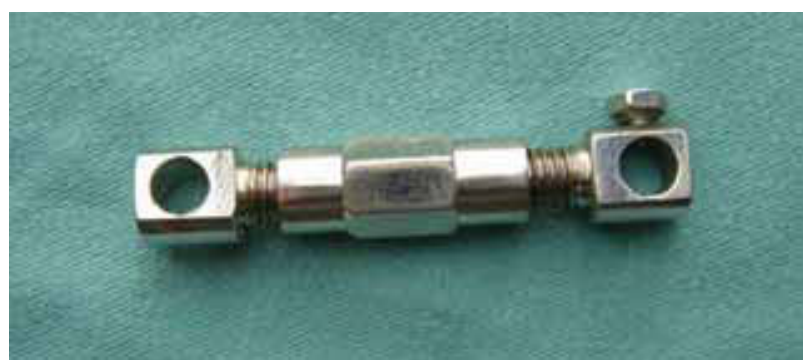

Reduction rod

decoupling of the rod and screw. The patient complained only of low back pain and did not experience neurological deficit. The instrumentation was removed and replaced with an SRS system. He has returned to work, resuming all duties. In the SRS group, one patient experienced constant postoperative paresthesias on the anterolateral aspect of the right leg that did not exist preoperatively. The patient underwent a postoperative CT scan that showed a badly placed screw in the right pedicle of the lumbar 4 and was given a timely correction.

\section{DISCUSSION}

Isthmic spondylolisthesis is a defect in the pars interarticularis in the posterior column of the lumbar spine. It can cause spinal stenosis or lateral canal stenosis due to anterior slippage of the vertebral column and fibrocartilaginous mass at the isthmic defect. $^{7,8}$ Decompression causes segmental instability and requires stabilization. The use of pedicle screws has been effective in rigid fixation, segmental control, and posterior stabilization. 
In the history of reduction surgery for spondylolisthesis, the first successful procedure was performed by surgeon Paul Harrington who, in 1967, placed the rod of a Harrington system between the lamina of L1 and a bar fixed on the post iliac part. ${ }^{9} \mathrm{He}$ achieved the reduction by extending the rod. But through the long-term follow-up, the reduction was not satisfactory; the rate of reduction was 50\%-60\%. In 1986,

\section{Figure 8.}

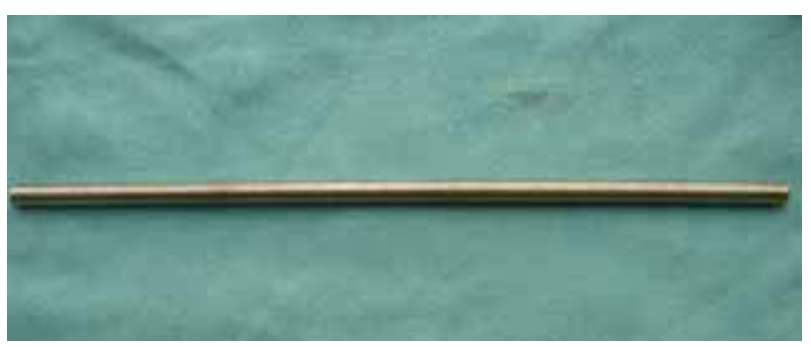

lliac bar

Matthiass reported on the posterior lever reduction system, in which reduction was conducted by the lever being placed at the intervertebral area. ${ }^{10}$ Due to the high risk of neurological injury, most surgeons had not accepted this technique. Harrington and Tullos ${ }^{9}$ first reported the technique of transpedicle screw fixation, and Roy-Camille et al. ${ }^{11}$ popularized the first practical method of pedicle screw fixation. Following the advocating of the pedicle screw technique, some disadvantages of the old methods emerged. Then Matthiass and Heine used the pedicle screw and plate to lift the slipped vertebra for the first time in 1986 and accomplished reduction. ${ }^{10}$ After the improvement of the pedicle screw, this technique was further developed. After the improvement of the plate, a variation of the pedicle screw system was used in surgery.

The reductive mechanism of the pedicle screw system is through the foothold of the superior and the inferior vertebral pedicle screw together, or of the inferior vertebral pedicle screw alone, to lift the slipped vertebra by fixing tightly the screw. However, some devices result in ineffective reduction due to flaws in their structure, such as the Steffee plate, for which fixation is difficult unless the pedicle screws stand in a line. Though the Steffee plate has better stability, its ability to open the intervertebral space is poor. Though a reduction and fixation (RF) system provides better reduction, the excessive stress concentrated on the angular part of the pedicle screw can rupture the structure of the device. And the fixation of the Dick's spinal fixation device is more complex, and so on.

The development of the transpedicle screw has provided control of the vertebral motion segment in each plane, resisting any type of load. This step in implant evolution was inevitable, because prior phases of implant development did not control each plane of motion segment stress. Continued clinical experience with various pedicle screw implant systems has led to ongoing improvements in system design to minimize implant failure rates and to improve ease of system application. Several studies reveal that fusion rates increase when rigid internal fixation is used $^{12,13}$ and that by using pedicle screws and plates or rods for stabilization, spinal arthrodesis can be limited to the diseased segments.

Although pedicle screw fixation opened a new horizon for spinal surgery by providing rigid fixation of the spine, it is a technically demanding procedure with potential complications including medical complications, hardware and technical problems, and long-term changes in the junctional motion segments. Pavlos et al. ${ }^{14}$ reported a retrospective study analyzing the complications and the problems developed during and after pedicle screw fixation in patients with spinal disorders and trauma. One hundred and twelve patients were treated using the Cotrel-Dubousset pedicle screw fixation system for degenerative disease, trauma, infection, and tumor of the lumbar or thoracolumbar spine. The average age of the patients was 47 years, and the average follow-up was 35 months. Hardware failures were observed in 12 patients $(10.7 \%)$, showing that placement of the pedicle screws in the thoracolumbar and lumbar spine is a technically demanding procedure. It should only be used by experienced and qualified surgeons who are aware of the risks associated with its use.

Iliac Bars Lever Reduction and Fixation System (IBLRFS) consists of the two pedicle screws, angular lift screws, reduction rod, iliac bar, and screw nuts A and B (Figures 4-10). The

\section{Figure 9.}

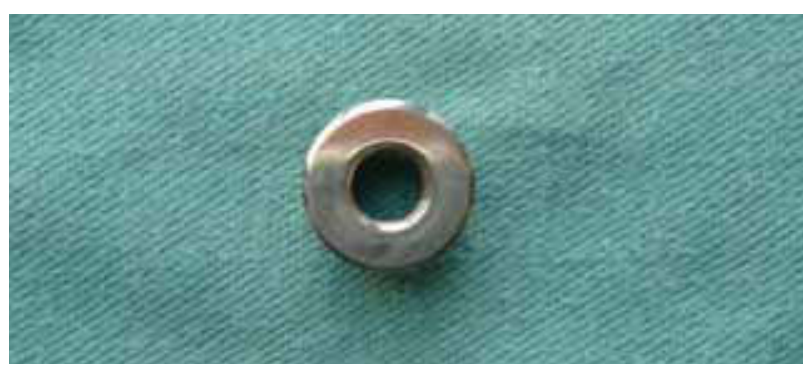

Screw nut $A$

reduction mechanism of the IBLRFS is to utilize the foothold of the proximal bar and reduce the slipped vertebra. The proximal bar is the keystone of this device. The angular lift plays a part in an anti-prolapse effect of the pedicle screw.

A previous study ${ }^{15}$ demonstrated the biomechanical superiority of the IBLRFS compared with other devices, such as the Steffee plate and RF system. In that study, 6 cadaver lumbosacral spines were used. Resistor strain slices were fastened at the lateral iliac plate beside the iliac bars and reduction rod, and an extensometer was fixed at intervertebral disc L5. The 
Figure 10.

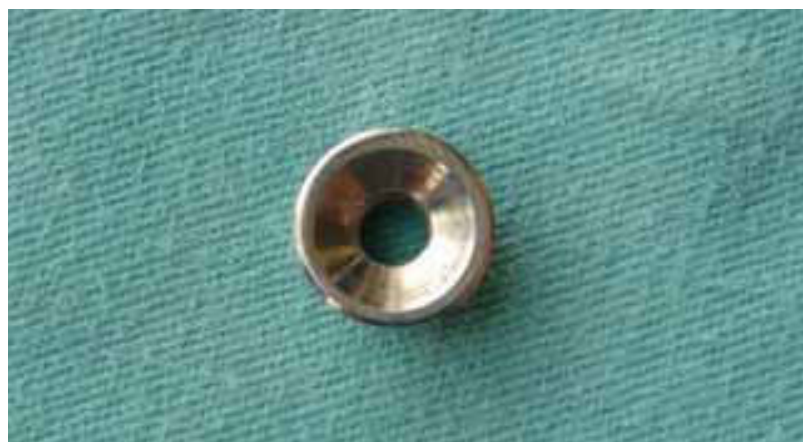

Screw nut B

biomechanical machine measured axial compressive loads of $500 \mathrm{~N}, 700 \mathrm{~N}$, and $900 \mathrm{~N}$. Mechanical analysis suggests that IBLRFS is a stable system, and the proximal bar is an important part of the foothold point that can endure $200 \mathrm{~N}$ if its diameter is $5 \mathrm{~mm}$. Under axial expressive load, the anterior straining at the L5-S1 intervertebral disc of the spine that was fixed by the IBLRFS was small and higher straining, distributed at the anterior iliac cortex of the proximal bar and the reduction rod. The patent right for using the IBLRFS for treatment of spondylolisthesis in China has been applied for (Granted NO.ZL200510056767.7).

In the current study, we placed emphasis on the outcomes of the use of the IBLRFS in symptomatic spondylolysis and also examined complications. We performed the fusion operations, using autogenous bone fusion as the basic principle. The overall recovery rate ranged from $42.9 \%$ to $100 \%$ (mean $88.3 \%$ ). Arlet et al. ${ }^{16}$ reported patients underwent single- or multiple-level circumferential lumbar fusion with anterior cages and posterior pedicle screws. The average age of the patients was 39.9 (26-57) years. The results suggest that harvesting a cylinder of autograft from the adjacent vertebral body is safe and efficient. Filling of the void defect with a beta-tricalcium phosphate plug does not preclude the use of posterior pedicle screw stabilization. Three hundred and sixty degrees fusion with both anterior and posterior fixation with instrumentation may be beneficial for these patients. ${ }^{17}$ The clinical results of this study show that iliac bars are suitable for bone fusion. There were no occurrences of nonunion in this series, and none of the patients experienced major complications including major vessel injury, neurologic damage, or nerve root injury in the IBLRFS group. Only one patient required further surgery to have the instrumentation removed for the decoupling of rod and screw.

Madan $^{18}$ analyzed the outcome of 44 patients who had decompression, pedicle screw-rod fixation, and fusion for Grades 1 and 2 spondylolytic spondylolisthesis. Results showed that posterolateral fusion has a better clinical outcome in low grades of isthmic spondylolisthesis, although posterior lumbar interbody fusion (PLIF) is more predictable in maintaining correction and achieving union. But Turner ${ }^{19}$ found that PLIF provided the highest fusion rate and the most satisfactory clinical results. It also can correct the deformity and provide early stabilization. In our study, it has shown satisfactory results because the IBLRFS only needs two pedicle screws which can decrease the risk of damage to the cauda equina and nerve root. The IBLRFS using intervertebral fusion stabilizes the spine anteriorly with pedicle screw instrumentation. This method of fusion dynamically decompresses the neural structures by distracting the vertebral bodies to their original disc height, fusing them into a single motion segment, and also possibly improving the fusion rate.

The disadvantages of the IBLRFS are as follows. The instruments are complex, and surgical steps are sophisticated, making the surgery more demanding. The placement of the halter and the support bar is especially a technically demanding procedure; it should be used only by experienced and qualified surgeons. The operative time was an average of 183.7 minutes in the IBLRFS group, but in the SRS group, it was only 156.6 minutes. On the other hand, compared with SRS, the incision of the IBLRFS was longer, extending to the $\mathrm{S} 3$, and the musculus sacrospinalis must be peeled off to the ala of ilium, which increases the risk of infection.

\section{CONCLUSIONS}

The IBLRFS can effectively improve the percentile degree of displacement, displacement angle, and sacral inclination, and can restore intervertebral space while being associated with minimal complications. Its short-term clinical results were satisfactory. A prospective, controlled and longitudinal study is warranted to clearly establish the exact outcome of the IBLRFS.

Yingze Zhang, MD, PhD, Yong Shen, MD, PhD, Dalong Yang, MD, Guochuan Zhang, MD, PhD, Chaohui Song, MD, Junming Cao, MD

From the Traumatic Center, The Third Hospital of Hebei Medical University (Y. Zhang, G. Zhang, and Song); and the Spinal Department, The Third Hospital of Hebei Medical University (Shen, Yang, and Cao)

No corporate funds were received to support this work. No benefits in any form have been or will be received from a commercial party related directly or indirectly to the subject of this manuscript.

Address correspondence and reprint requests to Yingze Zhang, MD, $\mathrm{PhD}$, Traumatic Center, The Third Hospital of Hebei Medical University, Shjiazhuang, Hebei, China (email: Doctoryangdalong@163.com).

This manuscript was submitted August 10, 2007, and accepted for publication November 8, 2007.

Protocol approval was received from the Hebei Medical University, China. 


\section{REFERENCES}

1. Bridwell KH. Utilization of iliac screws and structural interbody grafting for revision spondylolisthesis surgery. Spine. 2005;30:S88-S96.

2. Gibson JN, Waddell G. Surgery for degenerative lumbar spondylosis. Cochrane Database Syst Rev. 2005(18):CD001352.

3. Meyerding HW. Spondylolisthesis. Surg Gynecol Obstet 1932;54:371PubMed ;378.

4. Izumida $\mathrm{S}$, Inoue $\mathrm{S}$. Assessment of treatment for low back pain. Japanese Orthopaedic Association. J Jpn Orthop Assoc. 1986;60:391-394.

5. Suk S, Lee C-K, Kim W-J, et al. Adding posterior lumbar interbody fusion to pedicle screw fixation and posterolateral fusion after decompression in spondylolytic spondylolisthesis. Spine. 1997;22:210-220.

6. Bradford DS. Spondylolysis and spondylolisthesis in children and adolescents: current concepts in management. In: Bradford DS, Lonstein JE, Moe JH, Ogilvie JW, Winter RB, eds. Scoliosis and Other Spinal Deformities. Philadelphia: Saunders; 1987:410-421 PubMed.

7. Barash HL, Galante JO, Lambert CN, et al. Spondylolisthesis and tight ham strings. J Bone Joint Surg [Am]. 1970;52:1319-1328.

8. Schneck KF, Pon A. Biomechanics of posterior lumbar interbody fusion in spondylolisthesis. Clin Orthop. 1985;193:115-119.

9. Harrington PR, Tullos HS. Reduction of severe spondylolisthesis in children. South Med J. 1969,62:1-7.

10. Matthiass HH, Heine J. The surgical reduction of spondylolisthesis. Clin Orthop Relat Res. 1986;203:34-44.

11. Roy-Camille R, Saillant G, Mazel C. Internal fixation of the lumbar spine with pedicle screw plating. Clin Orthop. 1986;203:7-17.

12. Johnston II CE, Ashman RB, Baird AM, Allard RN. Effect of spinal construct stiffness on early fusion mass incorporation: Experimental study. Spine. 1990;5:908-912.

13. West III JL, Bradford DS, Ogilvie JW. Complications of the variable screw pedicle screw fixation. Spine. 1991;16:576-579.

14. Katonis P, Christoforakis J, Agisilaos C, et al. Complications and problems related to pedicle screw fixation of the spine. Clin Orthop. 2003;411: 86-94.

15. Zhang Y, MD, Song C, MD, Han J, MD. The design of Iliac Bars Lever Reduction and Fixation System for spondylolisthesis. Journal of Hebei Medical Uuniversity. 2005,26(4):258.

16. Arlet V, Jiang L, Steffen T, et al. Harvesting local cylinder autograft from adjacent vertebral body for anterior lumbar interbody fusion: surgical technique, operative feasibility and preliminary clinical results. Eur Spine J. 2006; 15:1352-1359.

17. Yuzawa Y, Kamimura M, Nakagawa $\mathrm{H}$, et al. Surgical treatment with instrumentation for severely destructive spondyloarthropathy of cervical spine. J Spinal Disord Tech. 2005;18:23-28.

18. Madan S, Boeree NR. Outcome of posterior lumbar interbody fusion versus posterolateral fusion for spondylolytic spondylolisthesis. Spine. 2002;27:1536-1542.

19. Turner JA, Ersek M, Herron L, et al. Patient outcomes after lumbar spinal fusions. JAMA. 1992;268:907-9113.

20. Yang K, King A. 1984 Volvo award in biomechanics: Mechanisms of facet load transmission as a hypothesis for low-back pain. Spine. 1984; 9:557.
21. Wuisman PI, van Dijk M, Smit TH. Resorbable cages for spinal fusion: an experimental goat model. J Neurosurg (Spine). 2002;97(4 Suppl):433439.

22. Latson L, Kuban B, Bryan J, et al. X-ray micro-computed tomography system: novel applications in bone imaging. Presented at the Engineering Medicine and Biology Society International Meeting, Cancun, Mexico, October 2, 2003.

23. Grass M, Kohler TH, Proksa R. 3D cone-beam CT reconstruction for circular trajectories. Phys Med Biol. 2000; 45:329-327.

24. Tye GW, Graham RS, Broaddus WC, Young HF. Graft subsidence after instrument-assisted anterior cervical fusion. J Neurosurg (Spine). 2002;97:186-192.

25. Benzel E, Ferrara L. Cervical interbody fusion. J Neurosurg. 2001; 94:180

26. DiAngelo DJ, Foley KT, Vossel KA, Rampersaud YR, Jansen TH. Anterior cervical plating reverses load transfer through multi-level strutgrafts. Spine. 2000;25:783-795.

27. Wang JC, Zou D, Yuan H, Yoo J. A biomechanical evaluation of graft loading characteristics for anterior cervical discectomy and fusion: A comparison of traditional and reverse grafting techniques. Spine. 1998; 23(22):2450-2454 